\title{
Simulation Model for Improving a Hospital
}

\author{
Grit Ngowtanasuwan, Porntip Ruengtam \\ Faculty of Architecture Urban design and Creative Arts, \\ Mahasarakham University, Thailand \\ grit_n@hotmail.com, rtip2004ster@gmail.com
}

\begin{abstract}
This article presents a method for design of improving medical record area in OPD of a governmental hospital case study, Mahasarakham Hospital, Thailand. By using a simulation model which is Petri Nets model for simulating and analysis of coming patients and their relatives in the hospital case study during 6:30-16:00 of the working days. The results found the application was applicable. Recommendations for the design of improving the waiting area case study were discussed and presented in this research.

Keywords: Out-patient department; medical record; simulation model; petrinets

eISSN: 2398-4279 ๔ 2016. The Authors. Published for AMER ABRA by e-International Publishing House, Ltd., UK.. This is an open access article under the CC BY-NC-ND license (http://creativecommons.org/licenses/by-nc-nd/4.0/). Peer-review under responsibility of AMER (Association of Malaysian Environment-Behaviour Researchers), ABRA (Association of Behavioural Researchers on Asians) and cE-Bs (Centre for Environment-Behaviour Studies), Faculty of Architecture, Planning \& Surveying, Universiti Teknologi MARA, Malaysia.

https://doi.org/10.21834/ajqol.v1i2.27
\end{abstract}




\subsection{Introduction}

Hospitals deal with human lives, which are often at risk and where everything depends on the quick response of medical and paramedical staff. Need for efficiency and productivity improvement for hospital services is always high as people wish to leave a hospital as early as possible with minimum expenditure on treatment as no one feels happy to stay or spend on treatment beyond what is necessary (Mital, 2012). Out-Patient Department (OPD) of a governmental hospital is an important place for people in their health services. Nowadays, there are large numbers of people and patients come to the OPD. Many times the OPD is congested. Causes of the congestion are numbers of coming patients to the OPD, coming relatives who come with patients to the OPD area. These matters lead to discomforting of the patients and people who come to use the services in the area such as inadequate chairs in the waiting area, limited space of the OPD, numbers of service staffs are not matched to numbers of coming patients. The medical record is a part of the OPD that has being faced this problem. Waiting areas of the medical records are congested by coming patients and relatives in the everyday morning, especially Monday. Sokolowski and Banks (2009) stated that hospitals today are facing an ever-increasing demand for their services.

This research presented a method for analysis and design of improving a medical record area in OPD of a governmental hospital case study, Mahasarakham Hospital, Thailand. By using a simulation model which is Petri Nets model for simulating and analysis of coming patients and their relatives in the hospital case study. The main objectives of this research were to study and survey behaviors of coming patients and their relatives who come to use services in an OPD of a hospital case study. To formulate and test a simulation model for simulating behaviors of coming patients and their relative over a period to the waiting area of the medical record of the hospital case study. To analyze and design improving the waiting area in the case study. This research covered a quantitative study of coming patients and their relatives who come to use services in the OPD case study. The hospital is a 300-bed governmental hospital of Thailand. Currently, the OPD of the hospital is facing congestion of people and operated 6:30-16:00 of working days.

\subsection{Literature Review}

"Out-Patient Department" (OPD) is a hospital department where patients received diagnoses and/or treatments, but they did not stay overnight. In general hospitals, there are medical provided services such as general medicine, general surgery, orthopedic surgery, gynecology, pediatrics, ophthalmology, dental department, and health prevention department. A "medical record" of OPD is the first point of contact with a patient and serves as the window to any health care services provided to the people or community. Patients have to start and register their services at this point. The medical record is used somewhat interchangeably to describe the systematic documentation of a single patient's medical history and care across time within one particular health care provider's jurisdiction (Wikipedia, 2013). Figure 1 illustrated relationships between areas in general OPD of hospitals.

Mandokhail (2007) had studied patient satisfaction towards an out-patient department in Banphaeo community hospital Samutsakhon, Thailand. The study found overall satisfaction was very good, but the improvement was needed in few of the accessibility and courtesy. 
A "simulation" is an applied methodology that can describe the behavior of that system using either a mathematical model or a symbolic model (Fishwick, 1995). Simply, simulation is the imitation of the operation of a real-world process or system over a period (Banks, 1998). Simulation is used when a real system cannot be engaged. This may happen when the real system might not be accessible, or it might be unacceptable to engage the system.

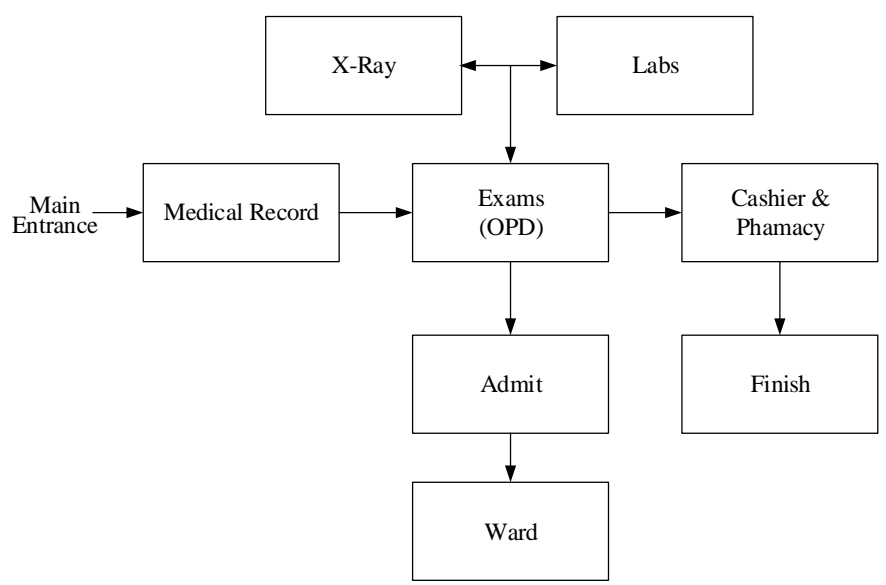

Figure 1: Relationship between areas in general OPD of hospitals

\begin{tabular}{|c|c|c|}
\hline $\begin{array}{l}\text { Modeling } \\
\text { Element }\end{array}$ & $\begin{array}{l}\text { Name of } \\
\text { Element }\end{array}$ & Description of Modeling Element \\
\hline & Place & $\begin{array}{l}\text { Places represent states of being. In construction, these are often } \\
\text { states of readiness. Places are connected to transitions via arcs. } \\
\text { Places hold tokens which can be added to or removed from tokens } \\
\text { by firing of transitions. }\end{array}$ \\
\hline & Transition & $\begin{array}{l}\text { Transitions are actions which change the state of the system. In } \\
\text { Petri Net jargon, transitions are said to fire as their action takes } \\
\text { place. In construction, transitions usually model activities of } \\
\text { operations. }\end{array}$ \\
\hline & Arc & $\begin{array}{l}\text { Arcs (Directed Arcs or Arrows) indicate the direction resources } \\
\text { (tokens) move when an action (firing of a transition) takes place. }\end{array}$ \\
\hline & Token & $\begin{array}{l}\text { Tokens represent resources or conditions within Petri Net. In } \\
\text { construction, they usually symbolize resources of operations. } \\
\text { Tokens reside within places and move between places via } \\
\text { transitions. Token movement updates Petri Nets marking. }\end{array}$ \\
\hline
\end{tabular}

Figure 2: Petri Net Modeling elements

"Petri Nets" (PNs) model is a formal graphical modeling tool which has been widely used to model various types of systems. Petri Nets were first developed by Carl Adam Petri and originally described in his doctoral thesis in 1962 (Petri, 1962). PNs is both a graphical and mathematical modeling tool. A Petri Nets is a bipartite directed and weighted graph consisting of two kinds of nodes called places and transitions, including another two elements, arcs, and 
tokens (see Figure 2). The location of resources (tokens) in a PNs network at any point in time is referred to as the marking of the net at that instant.

Wakefield and Sears (1997) had applied the Petri Nets model for simulation and modeling of construction systems. The results found the model can be used effectively for modeling construction systems and were discussed for improving the construction productivity.

Grit and Porntip (2013) had presented a simulation model of coming people in medical record area in OPD of a Governmental Hospital using Petri Nets model. The outputs of the simulation were used to improve people services in the area case study.

\subsection{Methodology}

Model Development of the Medical Record Case Study: Currently, the general process of service was started by a patient come to the medical record area. He would go to queue card counter for taking a queue number at the first point. Then, he (and his relative) would go to wait for a call from a service counter at the waiting area where provided chairs for patients and their relatives. About a few minutes, he would be called by a service counter, and he would go to stand in front of the counter. After a few minutes, he would go out of the area to an exam room. Figure 3 presented the plan of the medical record area. In the medical record of the hospital case study, one queue card counter and two service counters were provided for daily service. Forty-eight seats were provided for coming patients and their relatives in the waiting area.

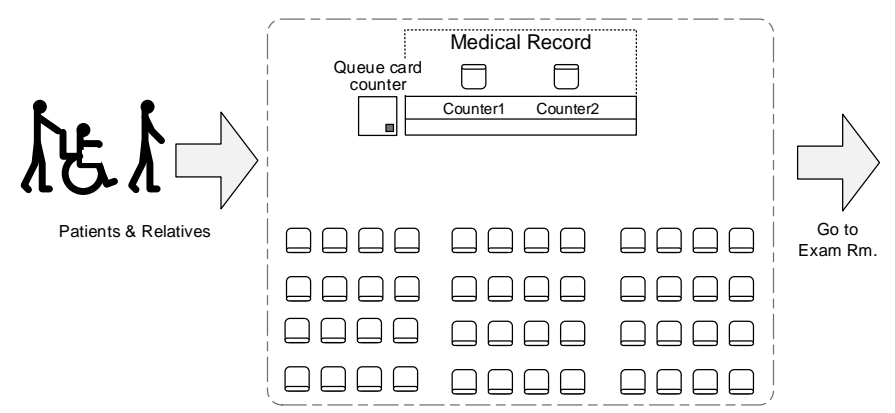

Figure 3: Medical record plan of the hospital case study

\subsection{Data collection}

Data collection in this research was studied in the period of November and December 2012 during 6:30 to 16:00 of working days (Monday-Friday). Number and time of each coming patient and relatives to the medical record area were collected for estimating the probability distribution of the inter-arrival time. Service times of service counters in the medical record area were collected for estimating the probability distribution of the service time. From observations by the researcher in the area, service time of taking a queue card number took only two or three seconds. Therefore, researcher assumed that they took three seconds $(0.05$ minutes) constantly without probability distribution. An example of data collection was shown in Table 1. 
From the collected data, researcher inputted the data to a personal computer by using probability distribution fitting software. The output found the best fit of a probability distribution for the inter-arrival time of coming patients to the area was "exponential distribution" (EXPO(1.06). A probability distribution for service time of a service counter was "lognormal distribution" (LOGN $(1.86,1.11)$ as shown in Figure 4 and 5 respectively.

Table 1: Example of data collection (Monday, 17 Dec 2012)

\begin{tabular}{ccccc}
\hline Patient no. & $\begin{array}{c}\text { no. of relative } \\
\text { (person) }\end{array}$ & Arrival time & $\begin{array}{c}\text { Inter-arrival time } \\
\text { (min.) }\end{array}$ & $\begin{array}{c}\text { Service time } \\
\text { (min.) }\end{array}$ \\
\hline 1 & 0 & $6: 30: 00$ & 5.00 & 1.43 \\
2 & 0 & $6: 35: 00$ & 5.00 & 1.55 \\
3 & 0 & $6: 40: 00$ & 2.00 & 0.88 \\
4 & 1 & $6: 42: 00$ & 1.00 & 1.40 \\
5 & 3 & $6: 43: 00$ &. & 1.63 \\
. &. &. &. &. \\
. & - & - &. &. \\
. &. &. & - &. \\
517 & 1 & $15: 25: 00$ & 0.50 & 1.57 \\
518 & 2 & $15: 25: 30$ & 3.50 & 0.75 \\
519 & 0 & $15: 29: 00$ & 2.00 & 2.47 \\
520 & 0 & $15: 31: 00$ & 9.00 & 1.28 \\
521 & 0 & $15: 40: 00$ & - & 2.67 \\
\hline
\end{tabular}

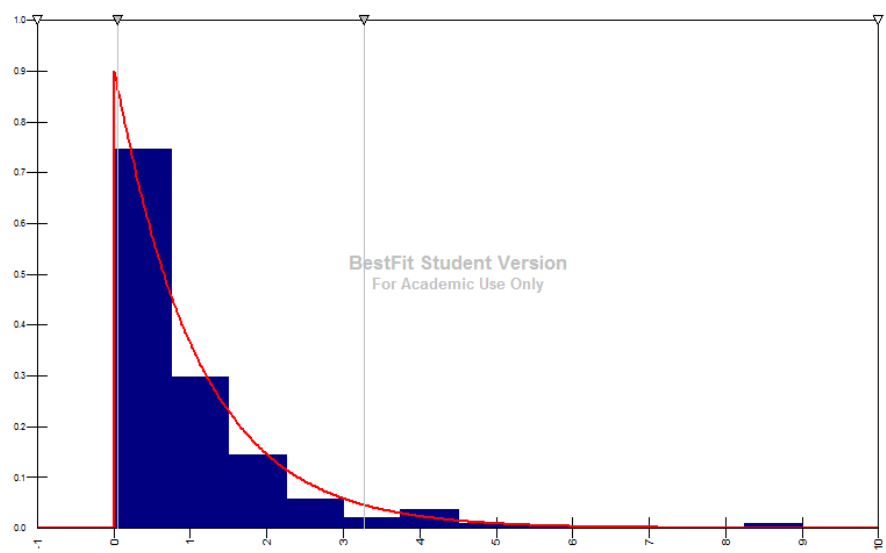

Figure 4: "Exponential distribution" for inter-arrival time of coming patients to the area

\subsection{Model formulation}

Tools for model formulation in this research were a personal computer and Petri Nets simulation software. The interface of the software was called for input data. According to the medical record plan, as shown in Figure 3 and the explained process of service, a simulation model, which is Petri Nets model was formulated. According to the collected data from the example of Monday (17 Dec. 2012), service duration of the medical record was 6:30 to 15:43 (553 min.) and total coming patients to the area was 521 patients. The model was started from a first place where represented "patients" with 521-capacity and 521-marking connected 
by an arc to a transition which meant action of patient "arrival" with an exponential distribution, EXPO(1.06). And then, a second place "queue card counter" with 1-capacity and 0 -marking connected by an arc to a transition of "queuing up" with 0.05 -minute constant action. After that went to a third place "waiting area" with 48-capacity and 0-marking. From the waiting area, the connection was split to be two arcs service counter 1 and 2 with a lognormal distribution, $\operatorname{LOGN}(1.69,1.06)$ for both counters. Finally, the connection was combined from the two counters to the last place called "going to exam rooms" with 521capacity and 0-marking. A completed simulation model in this research was shown in Figure 6.

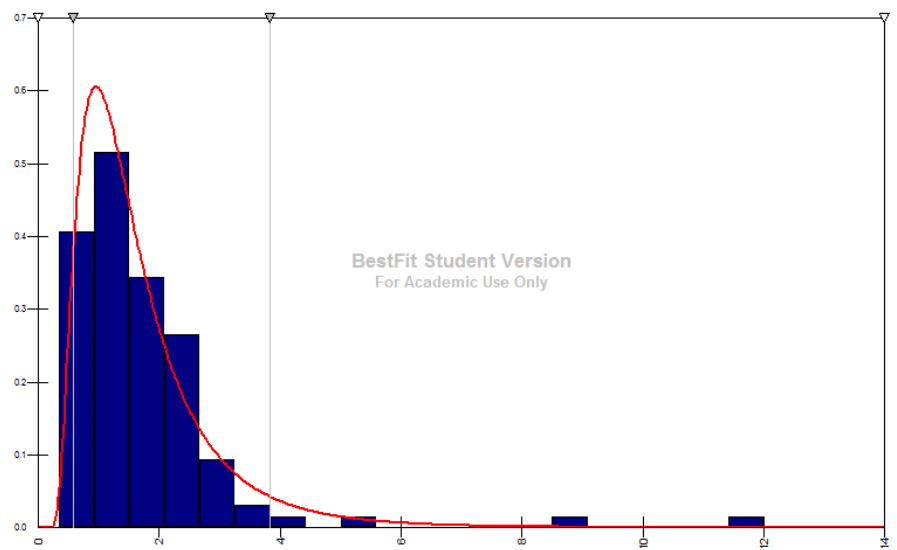

Figure 5: "Lognormal distribution" for service time of a service counter

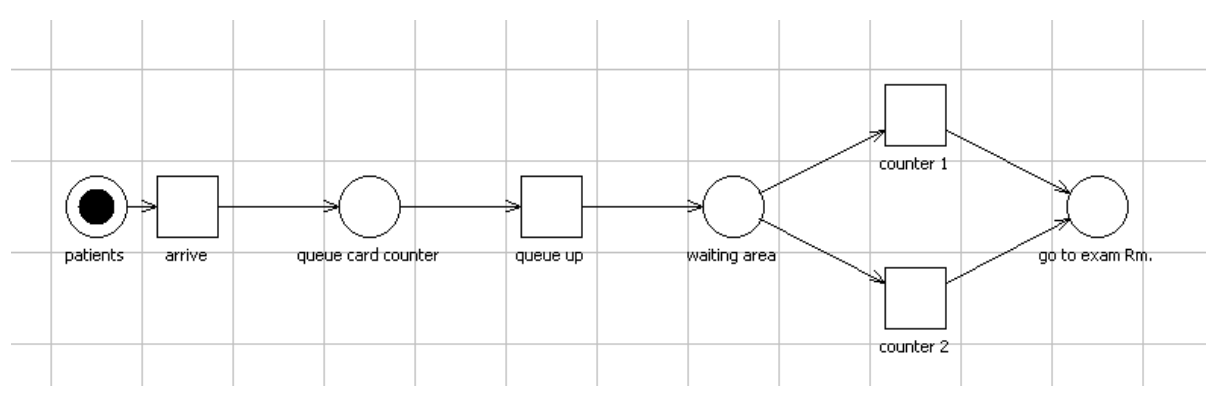

Figure 6: Petri Nets Model of the medical record area of the OPD case study

\subsection{Experimentation of the model}

Testing run of the formulated simulation model was tested for checking internal mechanism. A group of experts was requested for checking verification of the model in this research. More than 30-cycles were run for checking model validation of the formulated model. System durations per day (30-cycles run) of the model were tested for $95 \%$ confidence that the average duration equal to $553 \mathrm{~min}$. (Actual system duration of the collected data in $17 \mathrm{Dec}$. 
2012, Table 1), hypothesis $\mathrm{HO}: \square=553, \mathrm{H} 1: \square \neq 553$ was tested. Result failed to reject $\mathrm{H} 0$ $(\mathrm{N}=30$, Mean $=555.3, \mathrm{SD}=6.254, \mathrm{t}=2.014$, Sig.2-tailed $=0.053>0.05)$. Therefore, the average system duration of the model equal to the actual system duration (553 min.).

Experimentation with the model in the research, the model was modified to be four simulation scenarios for running different results. Because researcher would like to find out an optimum number of service counters by simulating a number of the service counter to be one, two, three, and four counters respectively. The four simulation scenarios of the 4-experimental run models were shown in Figure 7.

Simulation 1
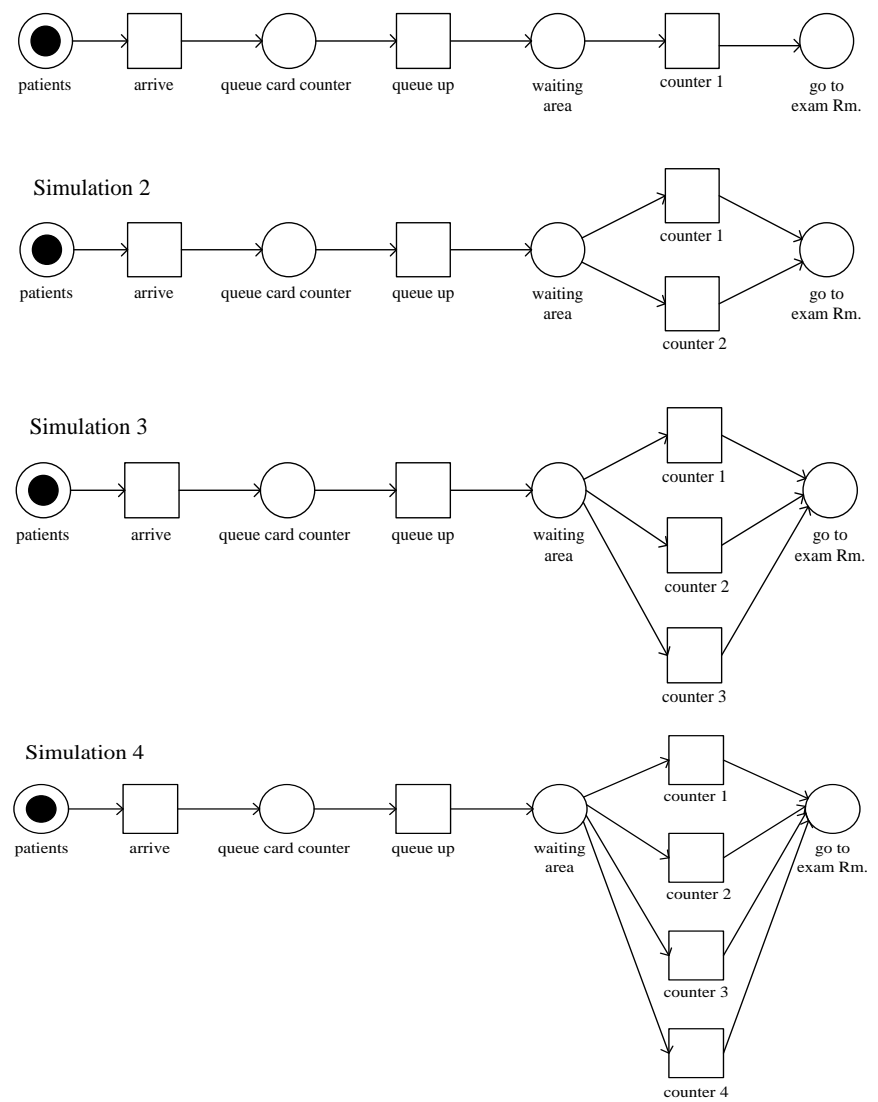

Figure 7: 4-modified models for the four simulation scenarios of the medical record

\section{Results and Discussions}

Results in this research were classified to be two parts:

\subsection{Results from field observations}

From observations in the area of the hospital case study and the collected data, ratio numbers between the total number of relative and the total number patient for each survey date were 0.38 to 0.44 ( 0.4 in average). Therefore, in this research researcher resulted a total number of 
people (patients and their relatives) in the area of the case study was 1.4 of the number of patients per day. A maximum number of coming patients was in the morning period of Monday in a week during the period of 7:30-10:00 in the peak day. Moreover, two or three wheelchair patients came to the area case study per day. The wheelchair patients were treated as the same process as a general patient. The researcher found the wheelchair patients had been an obstruction of people-flow in the area. Therefore, the new design plan for improving the medical record area should include this problem in the design.

\subsection{Results from model experimentations}

The four modified models of four simulation scenarios were run for different results. The results were a maximum number of patients and their relatives in the waiting area, total waiting time per day, the idle time of each service counter per day, and total system duration per day for each scenario. Results were shown in Table 2.

Table 2: Results of the model experimentations

\begin{tabular}{|c|c|c|c|c|c|c|c|c|}
\hline \multirow{2}{*}{$\begin{array}{l}\text { Simulation } \\
\text { or } \\
\text { no. of } \\
\text { counter }\end{array}$} & \multirow{2}{*}{$\begin{array}{c}\text { Max. } \\
\text { patients in } \\
\text { the area } \\
\text { (person) }\end{array}$} & \multirow{2}{*}{$\begin{array}{l}\text { Patients \& } \\
\text { Relatives } \\
\text { (person) }\end{array}$} & \multirow{2}{*}{$\begin{array}{l}\text { Total } \\
\text { waiting } \\
\text { time } \\
\text { (min.) }\end{array}$} & \multicolumn{4}{|c|}{ Idle time (min.) } & \multirow{2}{*}{$\begin{array}{c}\text { Total } \\
\text { system } \\
\text { duration } \\
\text { (min.) }\end{array}$} \\
\hline & & & & Counter 1 & Counter 2 & Counter 3 & Counter 4 & \\
\hline 1 & $198-199$ & $277-279$ & 175.3 & $0.16-0.18$ & - & - & - & $875-890$ \\
\hline 2 & $16-17$ & $22-24$ & 2.5 & $0.43-0.57$ & $0.43-0.57$ & - & - & $553-567$ \\
\hline 3 & $7-8$ & $10-11$ & 0.2 & $1.25-2.00$ & $1.25-2.00$ & $1.25-2.00$ & $\cdot$ & $553-567$ \\
\hline 4 & $4-5$ & $6-7$ & 0.08 & $2.36-3.25$ & $2.36-3.25$ & $2.36-3.25$ & $2.36-3.12$ & $553-567$ \\
\hline
\end{tabular}

\subsection{Conclusion}

This research presented a method for design of improving medical record area in OPD of a governmental hospital case study, Mahasarakham Hospital, Thailand. By using a simulation model, which is Petri Nets model for simulating and analysis of coming patients and their relatives in the hospital case study. The application was applicable. The results found that, in the present situation of the case study, two service counters were provided in the medical record, the maximum number of coming patients was in the morning period of Monday in a week. Peak numbers of the patients and their relatives were about 22-24 people in the waiting area during the period of 7:30-10:00 in the peak day.

In the results (Table 2), the simulation 2 and 3 (two and three counters) were candidates for selection in the design at present service. In the case of future service, researcher assumed a number of coming patients would be increased to $150 \%$ of present service. New data from the total number of coming patients (521x1.5=782 patients/day) and inter-arrival time $(\square=1.06 / 1.5=0.707)$ were inputted to the simulation 2 and 3 for comparisons of the results. The results found simulation 2 (two counters) could not serve the $150 \%$ of the future service because a total maximum person in the area (patients and their relatives) was 221- 
224 people. Simulation 3 (three counters) could serve the $150 \%$ of the future service. The results were presented as below (Table 3 ).

Table 3: Results from simulation 2 and 3 for $150 \%$ of present service

\begin{tabular}{ccccccccc}
$\begin{array}{c}\text { Simulation } \\
\text { or }\end{array}$ & $\begin{array}{c}\text { Max. } \\
\text { patients in } \\
\text { the area }\end{array}$ & $\begin{array}{c}\text { Patients } \\
\text { Ro }\end{array}$ & $\begin{array}{c}\text { Totatives } \\
\text { naiting } \\
\text { time }\end{array}$ & & Idle time (min.) & & $\begin{array}{c}\text { Total } \\
\text { system } \\
\text { duration }\end{array}$ \\
\cline { 6 - 7 } & (people) & (people) & (min.) & Counter 1 & Counter 2 & Counter 3 & (min.) \\
\hline 2 & $158-160$ & $221-224$ & 66.5 & $0.015-0.016$ & $0.015-0.016$ & - & $665-666$ \\
3 & $17-18$ & $24-25$ & 2.5 & $0.24-0.35$ & $0.24-0.35$ & $0.24-0.35$ & $505-515$
\end{tabular}

Recommendations for the design of improving the waiting area case study were:

- Three service counters of the medical record are optimum service for the hospital case study at present and future service (assume $150 \%$ of the number of coming patients would be increased in the future service).

- Minimum twenty-five seats in the waiting area are enough for coming patients and their relatives on the peak day of future service.

- Two spaces for wheelchair patients should be provided in the area.

Designed plan of improving the medical record area was shown in Figure 8.

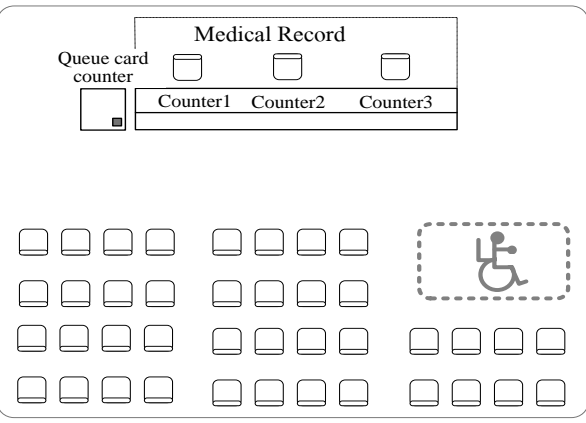

Figure 8: A designed plan (draft) for the medical record area in OPD of the governmental hospital

The applications of the simulation model can be applied to the other part of the OPD case study such as a waiting area for exam rooms of doctors, waiting area for cashier and pharmacy areas, medical associate laboratories. The application can also be applied for predictions of future problems when increasing numbers of coming patients and their relatives to the area. 


\section{Acknowledgement}

This research was supported funding by the research project grant provided by the faculty of Architecture Urban design and Creative Arts, Mahasarakham University, Thailand.

\section{References}

Amin Khan Mandokhail. (2007). Patient satisfaction towards outpatient department (OPD) services of medicine in banphaeo autonomous Hospital Samut Sakhon Province, Thailand Bangkok. Thesis, Mahidol University, Thailand.

Banks, J. (1998). Handbook of simulation: Principles, methodology, advances, applications, and practice. New York: Wiley \& Sons, Inc.

Fishwick PA. (1995). Simulation model design and execution: building digital worlds. Upper Saddle River, NJ: Prentice Hall..

Grit, N., \& Porntip, R. (2013). Applied simulation model for design of improving medical record area in out-patient department (opd) of a governmental Hospital, Procedia-Social and Behavioral Sciences. AicQoL 2013, Langkawi, $101,147-158$.

Mital, K. M. (2012). Strategic hospital management and medical information system: An Indian perspective, eight aims international conference on management. New Delhi.

Petri, C. A. (1962). "Kommunikation mit automaten" Ph. D. dissertation, University of Bonn, Bonn, West Germany; Also English translation: Greene, C. F. Jr. (1966). Communication with Automata. Supplement 1 to Technical Report RADC-TR-65-377, vol. 1, Rome Air Development Center, Griffiss Air Force Base, New York.

Sokolowsk,i A. J., \& Banks, M. C. (2009). Principles of modeling and simulation, a multidisciplinary approach. New Jersey: John Wiley \& Sons, Inc., Hoboken.

Wakefield, R. R., \& Sears, A. G. (1997). Petri Nets for simulation and modeling of construction systems. Journal of Construction Engineering and Management, 123, 105-112.

Wikipedia Website (2013). Available at: http://en.wikipedia.org/wiki/ Medical_record 